\title{
An Investigation on Polymerization of Ethylene by Ziegler-Natta Catalyst in the Presence of a Promoter: Polymerization Behavior and Polymer Microstructure
}

\author{
Y. Gholami1 ${ }^{1}$ M. Abdouss ${ }^{1 *}$, S. Abedi ${ }^{2}$, F. Azadi ${ }^{2}$, P. Baniani' ${ }^{2}$, M. Arsalanfar ${ }^{1}$ \\ ${ }^{1}$ Department of Chemistry, Amirkabir University of Technology, Hafez Ave, Tehran, Iran \\ ${ }^{2}$ Petrochemical R\&T Company of NPC (Tehran Center), Iranian Institute of Polymer and Petrochemical \\ Research, Pajouhesh Blvd., Karaj Highway, Tehran, Iran
}

Received: $2^{\text {nd }}$ October 2017; Revised: $5^{\text {th }}$ April 2018; Accepted: $26^{\text {th }}$ April 2018; Available online: $14^{\text {th }}$ November 2018; Published regularly: December 2018

\begin{abstract}
The effect of a halocarbon (ethyl chloride) as a promoter on a Ziegler-Natta catalyst composed of $\mathrm{TiCl}_{4}$ (catalyst), $\mathrm{AlEt}_{3}$ (activator) and $\mathrm{Mg}(\mathrm{OEt})_{2}$ (support) in the polymerization of ethylene have been investigated. In addition, the impact of this compound on the structural and thermal properties of the produced polyethylene has been studied. The catalyst activity and polymerization rate increased almost up to twice when a suitable molar ratio of ethyl chloride to triethylaluminum (TEA) was used. There was no change in the type of the profile of the polymerization rate during the polymerization time. A reduction in the polymer molecular weight was observed in the presence of the promoter and hydrogen. In addition, the MWD curve shifted toward lower values in the presence of ethyl chloride. Furthermore, a numerical method was used to obtain the most probable chain-length distribution, number average molecular weight and weight fraction corresponding to each site type in the presence and absence of the promoter. Since, the catalyst had an irregular shape, the produced polymer also showed a similar morphology. In addition, the promoter used in the polymerization did not have any effect on the produced polymer morphology. The DSC results indicated that the presence of the promoter in the polymerization led to a decrease in the melting point of the produced polymer; whereas, there were no remarkable changes in the crystallization temperature of the polymers. Copyright ( $) 2018$ BCREC Group. All rights reserved
\end{abstract}

Keywords: Halocarbon; Polymerization; Polyethylene; Promoter; Ziegler-Natta Catalyst

How to Cite: Gholami, Y., Abdouss, M., Abedi, S., Azadi, F., Baniani, P., Arsalanfar, M. (2018). An Investigation on Polymerization of Ethylene by Ziegler-Natta Catalyst in the Presence of a Promoter: Polymerization Behavior and Polymer Microstructure. Bulletin of Chemical Reaction Engineering \& Catalysis, 13 (3): 412-419 (doi:10.9767/bcrec.13.3.1574.412-419)

Permalink/DOI: https://doi.org/10.9767/bcrec.13.3.1574.412-419

\section{Introduction}

Polyethylene is used in a wide variety of applications due to its versatile physical and chemical properties. The heterogeneous ZieglerNatta catalysts are the main systems among

* Corresponding Author.

E-mail: phdabdouss44@aut.ac.ir (M. Abdouss) polyethylene catalysts, however, one of the disadvantages of these catalysts is that they show low activity in the presence of hydrogen as a chain transfer agent [1-3]. Hydrogen deactivates some potentially active sites, probably via irreversible adsorption on these sites, even before polymerization is initiated [4]. In recent years, the promoters are used to improve the performance of the Ziegler-Natta catalysts in the 
polymerization of ethylene [6]. Generally, the promoters are halocarbons (organohalides) which not only increase the activity of the catalyst, but also have a low toxicity and are easily separated from the polymer due to very low value of their boiling points [6].

All halocarbons, especially mono-chlorides, such as $\mathrm{C}_{6} \mathrm{H}_{11} \mathrm{Cl}, \mathrm{C}_{6} \mathrm{H}_{5} \mathrm{Cl}$, and $\mathrm{n}-\mathrm{C}_{4} \mathrm{H}_{9} \mathrm{Cl}$, are suitable to be used along with titanium-based catalysts [7]. The nature and amount of the halocarbon have significant impacts on the catalyst activity. Optimum molar ratio of halocarbon to titanium (or halocarbon to TEA) significantly depends on the type of promoters, so that the catalyst activity could be increased by more than twice when a suitable molar ratio of halocarbon to titanium is utilized. Conversely, the polymerization process may be terminated if the suitable molar ratio is not implemented [7]. Yet, no specific hypothesis is proposed to fully explain the mechanism by which halocarbon affects the process performance. It seems that halocarbons may form a weak bond to the transition metal catalyst and change its oxidation number [8]. Changing the oxidation number toward the active oxidation numbers significantly increases the catalyst activity; however, a change in the opposite direction results in a reduction in its activity. Studies showed that those halocarbons added to the catalysts can also interact with the co-catalyst (activator).

Totally, TEA is usually presented in the dimeric form. When halocarbons containing geminal halogen are used as promoters, the halogens can react with aluminum atom and convert dimeric form of TEA into a monomeric one (Figure 1). Thus, more ethyl groups are available for the reduction of catalyst leading to an increased catalyst activity [9]. The addition of halocarbon not only improves the activity of the catalyst in the presence of hydrogen but also causes some improvement in such polymer properties as its molecular weight and bulk density as well as adjustment of some problems such as the production of the fine particles [1011 .

Ethyl chloride (EC) is produced as a by product during the manufacturing of ZieglerNatta catalysts where it remains in hexane while it is recycling. This causes ethyl chloride to inadvertently introduce into the ethylene polymerization process cycle [12]. Since, the product of EC during the manufacturing of Ziegler-Natta catalysts is not yet to be known and a literature survey shows that no significant study is done on the microstructure of the polymers produced by the Ziegler-Natta cata- lyst in the presence of EC, the objective of this study is the investigation of the effect of ethyl chloride as a promoter on the polymerization behavior of ethylene and also its structural and thermal properties.

\section{Materials and Method}

\subsection{Materials}

Ethylene monomer (purity > $99.95 \%$ ), hexane $\left(\mathrm{H}_{2} \mathrm{O}<3 \mathrm{ppm}\right)$ and nitrogen (purity $>$ $99.99 \%$ ) were supplied from Linde (Germany), Pentane Chemical Industries (Iran) and Arkan Gas (Iran), respectively. Hydrogen (purity > $99.99 \%$ ), ethyl chloride and TEA were purchased from Merck (Germany).

\subsection{Catalyst Preparation}

The catalyst was prepared in a Buchi 1.0-1 steel jacket autoclave reactor (equipped with a mechanical seal stirrer) where titanium tetrachloride reacts with a support through a welldefined method. Reference 11 describes the details of this method [11].

The amounts of titanium and magnesium elements in the catalyst were measured by atomic absorption spectrometry (Shimadzu 6800 , Japan). A precise amount of the catalyst
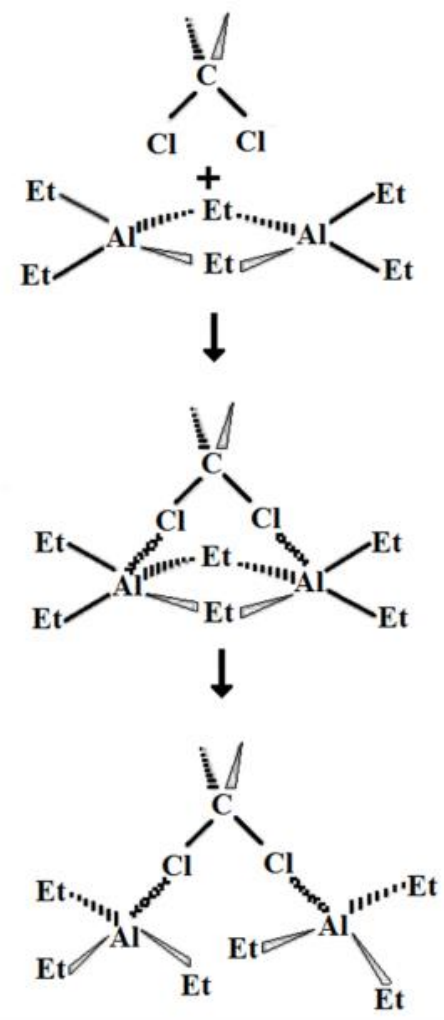

Figure 1. Formation of monomeric form of TEA in the presence of halocarbon 
(about 100-150 mg) was dissolved in $10 \mathrm{~mL}$ of $0.1 \mathrm{M}$ sulfuric acid solution and diluted to 100 $\mathrm{mL}$ with distilled water [13]. The chloride content was evaluated according to the Volhard's method [14].

\subsection{Polymerization Reaction Process}

Ethylene polymerization was carried out in the slurry phase at a constant pressure and temperature in a 1-L Buchi stainless steel reactor (Switzerland) equipped with a mechanical stirrer. Before the polymerization, a stream of nitrogen was applied to the reactor at a temperature of $110^{\circ} \mathrm{C}$ for $1.5 \mathrm{~h}$ in order to eliminate the possible pollutants, especially moisture and oxygen. After cooling the reactor to below the boiling point of hexane and ethyl chloride (about $10{ }^{\circ} \mathrm{C}$ ), it was fed with $500 \mathrm{~cm}^{3}$ of dried hexane under a limited stream of nitrogen. Next, $600 \mathrm{mg}$ of TEA was immediately injected into the reactor through a special syringe while the mixture was stirred (speed was 400 rpm). The prescribed amounts of cooled ethyl chloride (about $5{ }^{\circ} \mathrm{C}$ ) were added to the reactor each time and then the reactor temperature and ethylene pressure increased to $80{ }^{\circ} \mathrm{C}$ and 8.5 bars. After these steps, $1 \mathrm{mg}$ of catalyst was injected into the reactor. During the polymerization, ethylene was supplied continuously at the pressure of 8.5 bars and its consumption was measured by a mass flow meter (Brooks, Holland). To investigate the influence of hydrogen on the polymerization parameters, hydrogen was injected to the required amount ( 3 and 5 bar) before ethylene was applied. The polymerization reaction was continued for 2 hours and then, the reactor was discharged, and the powder polymer was dried in the air.

\subsection{Catalyst characterization}

The surface area, pore volume, and average pore radius of the catalyst were measured using BET apparatus (Corp. NOVA 2200, Version 7.11, USA) [15]. The DSC analysis was performed to measure the degree of crystallinity $\left(X_{c}\right)$ as well as melting and crystallization points $\left(T_{m}\right.$ and $\left.T_{c}\right)$ of the produced polymers [16]. The measurements were performed by a Mettler Toledo 822e calorimeter (USA) at the temperature rate of $10^{\circ} \mathrm{C} / \mathrm{min}$ under nitrogen atmosphere at the temperature range of 25-200 ${ }^{\circ} \mathrm{C}$.

The molecular weight and molecular weight distribution of the produced polymers were measured via the gel permeation chromatography (GPC) method by a PL Instrument PL220 (USA). The operating conditions were set according to reference 17. The morphologies of the catalyst and polymer powder were depicted using scanning electron microscopy (SEM) (Cam Scan MV 2300, UK). The catalyst yield was obtained in terms of the produced polyethylene (kg) per used catalyst (g) in the polymerization. The GPC curves of the produced polymers were separated to the Flory components via the deconvolution technique described in reference 18.

\section{Results and Discussion}

Table 1 shows the BET, and elemental analyses of the prepared catalyst. According to the table, the catalyst had a high value of surface area $\left(78 \mathrm{~m}^{2} / \mathrm{g}\right)$. The effect of ethyl chloride on the yield of the Ziegler-Natta catalyst $\left(\mathrm{AlEt}_{3} / \mathrm{TiCl}_{4} / \mathrm{Mg}(\mathrm{OEt})_{2}\right)$ and polymerization rate were studied. Table 2 shows the effect of various values of EC/TEA ratio on the catalyst yield. The results revealed that ethyl chloride had a noticeable effect on the catalyst yield, rising from about $35 \mathrm{~kg} \mathrm{PE} / \mathrm{g}$ Cat in the absence of ethyl chloride to about $51 \mathrm{~kg} \mathrm{PE} / \mathrm{g}$ Cat at the EC/TEA molar ratio of 0.5 .

According to Table 2, the increase of the EC/TEA ratio up to 0.5 promoted the catalyst activity; whereas, higher ratios led to a reduction in the catalytic activity. In fact, high amount of ethyl chloride poisons the catalyst system, probably because of the formation of a stable complex between this compound and $\mathrm{Ti}$ active center, so that the complexation of ethylene and the propagation of the polymer chain were inhibited [5,11].

Figure 2 illustrates the effect of various values of EC/TEA ratio on the polymerization rate of ethylene. As expected, the rate of the polymerization was higher in the presence of ethyl chloride, but it could not change the catalyst activity trend during the polymerization time. The maximum polymerization rate was observed at the molar ratio of 0.5 where the catalyst performance was a maximum. The reason for such an increase in the catalyst ac-

Table 1. Catalyst analysis results

\begin{tabular}{cc}
\hline Properties & Value \\
\hline Surface area $\left(\mathrm{m}^{2} / \mathrm{g}\right)$ & 78 \\
Pore volume $(\mathrm{mL} / \mathrm{g})$ & 0.26 \\
Average pore radius $(\AA)$ & 67.7 \\
$\mathrm{Ti}(\%)$ & 8.9 \\
$\mathrm{Mg}(\%)$ & 18.8 \\
$\mathrm{Cl}(\%)$ & 64.25 \\
\hline
\end{tabular}


tivity and polymerization rate is attributed to the oxidative effect of halocarbon compounds that results in a change in the oxidation state of the transition metal and facilitates the participation of active centers in the polymerization reaction [19].

Hydrogen usually is used as a chain transfer agent to control the molecular weight of polyolefin in the coordination polymerization. Based on Table 2, the catalyst yield showed a remarkable decrease in the presence of hydrogen. In fact, it reduced from $35.5 \mathrm{~kg} \mathrm{PE} / \mathrm{g}$ Cat in the absence of hydrogen to $4.92 \mathrm{~kg} \mathrm{PE} / \mathrm{g}$ Cat and $1.76 \mathrm{~kg} \mathrm{PE} / \mathrm{g}$ Cat in the presence of hydrogen at pressures of 3 and 5 bar, respectively. The main reason for such a decline in the catalyst yield was the reduction of the partial pressure of the monomer in the polymerization of ethylene when the amount of hydrogen (chain transfer agent) increased. Furthermore, the slow addition of the monomer to the catalyst-hydrogen bond formed in the step of the chain transfer to hydrogen had an adverse effect on the catalyst yield [4].

Hydrogen also reduced the polymerization rate. It was about $35 \mathrm{~g} / \mathrm{h}$ in the absence of hy-

Table 2. Effect of EC/TEA ratio and hydrogen on catalyst yield

\begin{tabular}{ccc}
\hline $\begin{array}{c}\text { EC/TEA } \\
\text { (molar ratio) }\end{array}$ & $\begin{array}{c}\mathrm{H}_{2} \\
\text { (bar) }\end{array}$ & $\begin{array}{c}\text { Yield } \\
(\mathrm{kg} \mathrm{PE} / \mathrm{g} \text { Cat })\end{array}$ \\
\hline 0 & 0 & 35.5 \\
0.25 & 0 & 40.6 \\
0.5 & 0 & 51.3 \\
0.75 & 0 & 43.7 \\
1.0 & 0 & 31.5 \\
0 & 3 & 4.92 \\
0.5 & 3 & 8.12 \\
0 & 5 & 1.76 \\
0.5 & 5 & 3.34 \\
\hline
\end{tabular}

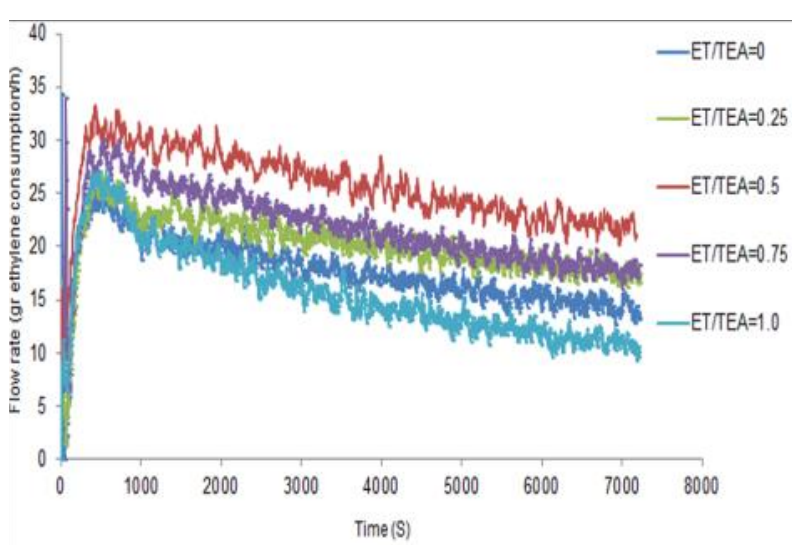

Figure 2. Effect of ethyl chloride on polymerization rate drogen while it fell down to about $25 \mathrm{~g} / \mathrm{h}$ and $10 \mathrm{~g} / \mathrm{h}$ in the presence of hydrogen at a pressure of 3 and 5 bars, respectively (Figure 3). Although hydrogen has a significant negative effect on the performance of the catalyst, the promoter can remarkably improve the catalyst performance in the presence of hydrogen (Figure 3 and Table 1).

Table 3 shows the results of the GPC tests for the synthesized polymers. Hydrogen has a significant effect on the molecular weight, reduced from approximately $24.1 \times 10^{5}(\mathrm{~g} / \mathrm{mol})$ in the absence of hydrogen to about $1.39 \times 10^{5}$ $(\mathrm{g} / \mathrm{mol})$ and $0.65 \times 10^{5}(\mathrm{~g} / \mathrm{mol})$ in the presence of hydrogen at a pressure of 3 bar and 5 bar, respectively. According to Table 3, the addition of ethyl chloride reduced the molecular weight of the polymer. Accordingly, the molecular weight decreased from $24.1 \times 10^{5}(\mathrm{~g} / \mathrm{mol})$ in the absence of ethyl chloride to $16 \times 10^{5}(\mathrm{~g} / \mathrm{mol})$ in the presence of ethyl chloride. This reduction may be attributed to the increased operations of the chain-transfer agent. In fact, TEA also acts as a chain transfer agent [20]. The dimmer form of TEA is transformed into a monomeric form in the presence of promoter improving the order of TEA in the polymerization system. This may also improve the role of chain transfer agent (TEA) and ultimately increases the rate of termination reactions. Since the molecular weight is directly related to the termination reactions, a reduction in the molecular weight of the polymer is observed [9].

The produced polymers showed a broad molecular weight distribution which was generally assumed to be caused by more than one active site type in the catalyst. Each active site produces polymer with narrow molecular weight distribution that follow a Schultz-Flory distribution model and are called Flory components. The molecular weight distribution index

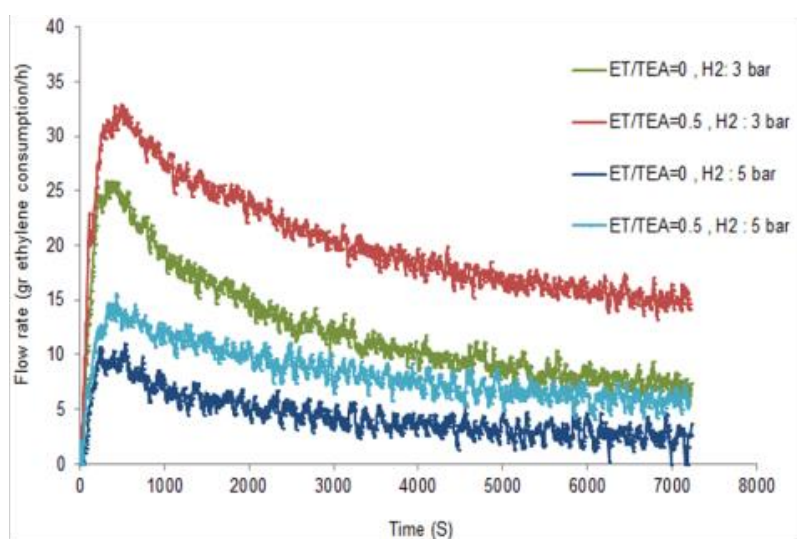

Figure 3. Effect of hydrogen on ethylene polymerization rate 
of such components is typically equal to 2 . The deconvolution of the experimental GPC data is useful for obtaining information about the polymerization kinetics and catalyst system properties. This technique also provides information on the number average molecular weight $(\mathrm{Mn})$, created by each site type and their corresponding weight fraction. Therefore, this technique can be used to study the effect of ethyl chloride on the polymer microstructure.

The results of the deconvolution of the GPC curves into Flory components are presented in Figure 4 (A, B) and Table 4 for two polyethylene samples. The results indicate that five Flory components are sufficient to describe the MWD curve of polyethylene. Therefore, it is reasonable to assume that the polyethylene samples have been produced by a catalyst containing five different site types.
Figure 4A illustrates different molecular weights that are produced by various site types. The sites of I and II produce the lowest molecular weight; whereas, the IV and V types produce the highest molecular weight and those of III have an average values. The active site of III has the most contributions among other active sites to the production of polymers. Table 4 shows that changes in the ratio of ethyl chloride to TEA had directly impact on the number average molecular weight created by each type of site and also their corresponding weight fraction. By comparing the samples of polymers A and B in the table, it was observed that the weight fractions of the active sites of I and II which produce polymers with lower molecular weight increased with increasing the EC/TEA molar ratio; whereas, that of III and IV which produce higher molecular weights de-

Table 3. Effect of ethyl chloride and hydrogen on molecular weight and molecular weight distribution of produced polymers

\begin{tabular}{cccccccc}
\hline $\begin{array}{c}\text { EC/TEA } \\
\text { (molar ratio) }\end{array}$ & $\begin{array}{c}\text { Hydrogen } \\
(\mathrm{bar})\end{array}$ & $\begin{array}{c}\mathrm{Mw} \times 10^{-5} \\
(\mathrm{~g} / \mathrm{mol})\end{array}$ & $\begin{array}{c}\mathrm{Mn} \times 10^{-5} \\
(\mathrm{~g} / \mathrm{mol})\end{array}$ & $\begin{array}{c}\mathrm{Mp} \times 10^{-5} \\
(\mathrm{~g} / \mathrm{mol})\end{array}$ & $\begin{array}{c}\mathrm{Mz} \times 10^{-5} \\
(\mathrm{~g} / \mathrm{mol})\end{array}$ & $\begin{array}{c}\mathrm{Mz}+1 \times 10^{-5} \\
(\mathrm{~g} / \mathrm{mol})\end{array}$ & $\begin{array}{c}\mathrm{MWD} \\
0\end{array}$ \\
\hline 0 & 24.1 & 6.2 & 10 & 49.5 & 67.9 & 3.9 \\
0.25 & 0 & 20.1 & 3.9 & 10.3 & 66.1 & 237.0 & 5.1 \\
0.5 & 0 & 16.8 & 2.7 & 10.7 & 35 & 47.8 & 6.2 \\
0.75 & 0 & 18.6 & 3.5 & 9.8 & 41 & 57.5 & 5.3 \\
1.0 & 0 & 16 & 2.5 & 9.4 & 37 & 51.7 & 6.3 \\
0 & 3 & 1.39 & 0.29 & 0.59 & 9.1 & 61.8 & 4.7 \\
0.5 & 3 & 1.35 & 0.21 & 0.58 & 18 & 46.9 & 6.4 \\
0 & 5 & 0.65 & 0.12 & 0.35 & 2.2 & 4.6 & 5.2 \\
0.5 & 5 & 0.64 & 0.10 & 0.32 & 2.8 & 6.6 & 6.5 \\
\hline
\end{tabular}

Table 4. Data on calculated MWD parameters of PE (Polymerization conditions: $\mathrm{PC}_{2}=3.5$ bar, TEA (cocatalyst), Time $=2 \mathrm{~h}, \mathrm{PH}_{2}=5$ bar, $\mathrm{Temp}=80{ }^{\circ} \mathrm{C}$ )

\begin{tabular}{|c|c|c|c|c|}
\hline $\mathrm{PE}$ & $\begin{array}{c}\text { EC/TEA } \\
\text { (molar ratio) }\end{array}$ & Flory component & $\begin{array}{c}\mathrm{Mn} \times 10^{-3} \\
(\mathrm{~g} / \mathrm{mol})\end{array}$ & Portion of Flory component (\%) \\
\hline \multirow{5}{*}{ A } & \multirow{5}{*}{0} & $\mathrm{I}$ & 1.15 & 0.026616 \\
\hline & & II & 4.21 & 0.123483 \\
\hline & & III & 14.19 & 0.42242 \\
\hline & & IV & 38.86 & 0.335461 \\
\hline & & $\mathrm{V}$ & 133.96 & 0.092021 \\
\hline \multirow{5}{*}{$\mathrm{B}$} & \multirow{5}{*}{0.5} & $\mathrm{I}$ & 0.85 & 0.035989 \\
\hline & & II & 3.66 & 0.137008 \\
\hline & & III & 13.29 & 0.417994 \\
\hline & & IV & 37.20 & 0.316952 \\
\hline & & $\mathrm{V}$ & 132.13 & 0.092057 \\
\hline
\end{tabular}


creased. In addition, $\mathrm{Mn}$ of all of the active sites decreased which finally resulted in the decrement of the Mn of the synthesized polymer (in accordance with the results of Table 3). For a better comparison, the molecular weight distribution of the produced polymers regardless of their active sites has been presented in Figure 5. As indicated in this figure, MWD curve shifted toward lower values in the presence of ethyl chloride.

Values of $T_{m}, T_{c}$, and $X_{c}$ of the produced polymers are shown in Table 5. The addition of
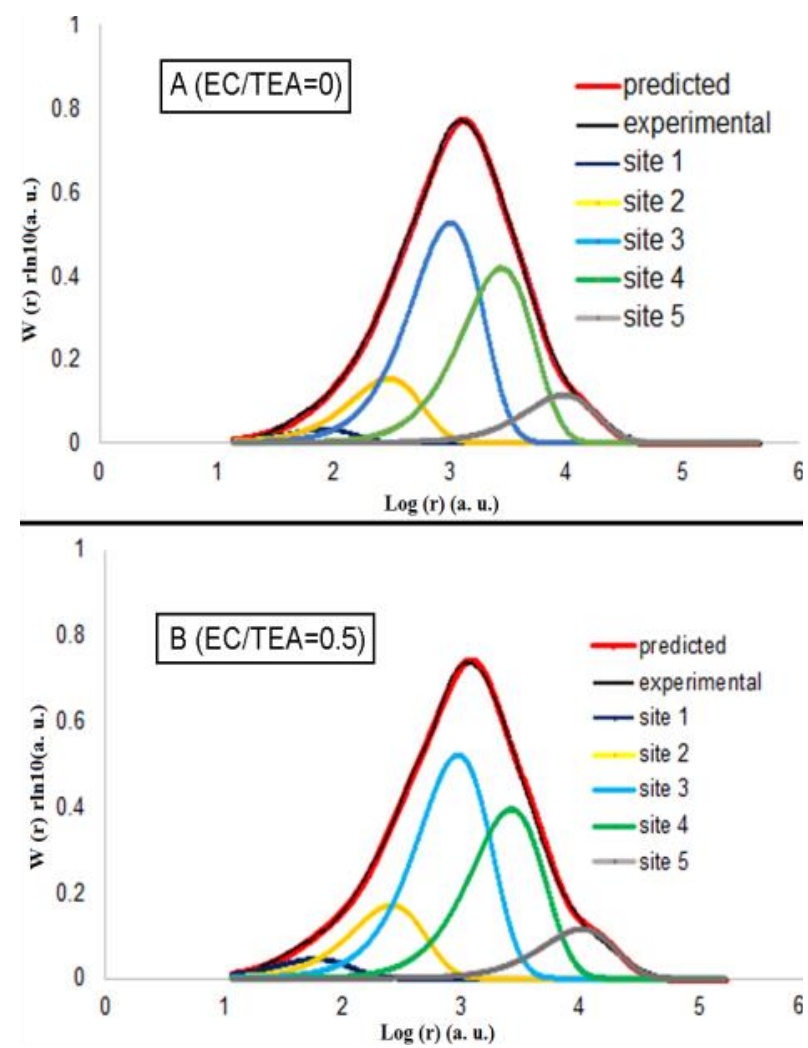

Figure 4. Deconvolution of an experimental polyethylene chain length distribution into five most probable chain-length distributions

Table 5. Results of DSC analysis

\begin{tabular}{ccccc}
\hline EC/TEA & $\mathrm{H}_{2}$ (bar) & $T_{m}\left({ }^{\circ} \mathrm{C}\right)$ & $T_{c}\left({ }^{\circ} \mathrm{C}\right)$ & $X_{c}(\%)$ \\
\hline 0 & 0 & 137.21 & 119.24 & 59.17 \\
0.25 & 0 & 136.72 & 119.67 & 58.91 \\
0.5 & 0 & 136.68 & 119.39 & 57.05 \\
0.75 & 0 & 136.88 & 119.2 & 56.38 \\
1.0 & 0 & 136.62 & 119.61 & 49.43 \\
0 & 3 & 135.47 & 120.17 & 63.41 \\
0.5 & 3 & 135.13 & 120.31 & 59.38 \\
0 & 5 & 133.98 & 118.92 & 79.13 \\
0.5 & 5 & 133.52 & 119.05 & 66.14 \\
\hline
\end{tabular}

ethyl chloride decreased the melting temperature and crystallinity $\left(X_{c}\right)$ of the produced polymer. The melting point slightly reduced in the presence of hydrogen and ethyl chloride. Meanwhile, there were no remarkable changes in the crystallization temperature of the polymers. The crystallization of the samples with high molecular weight is slightly affected by the average molecular weight and molecular weight distribution. In fact, it is dependent to a major extent by the degree of chain branching [21]. The lower melting point and $X_{c}$ values in the presence of ethyl chloride can be related to the production of a number of polymers with chain branches.

Figure 6 displayed the SEM images of the produced polymer powder. As the figure exhibits, the promoter used in the polymerization did not have any effect on the produced polymer morphology. In fact, the produced polymers showed the similar morphology.

\section{Conclusion}

An optimum molar ratio of ethyl chloride promoter to TEA (0.5) noticeably promoted the activity of the Ziegler-Natta catalyst system

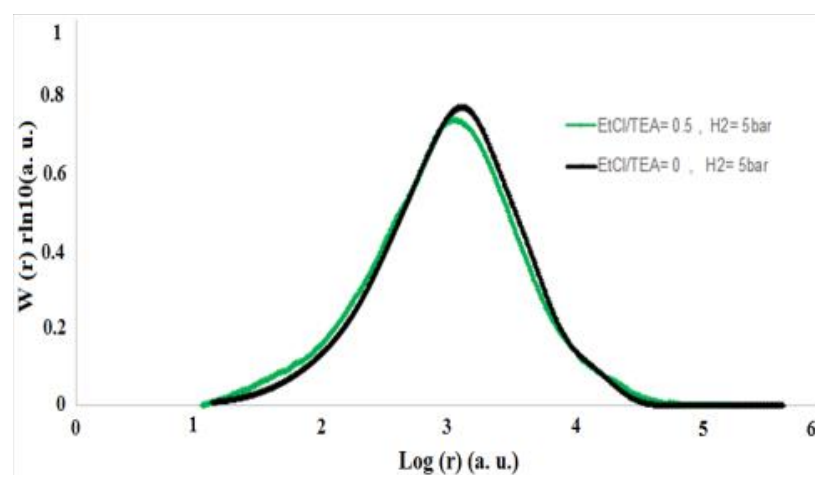

Figure 5. Molecular weight distribution curves of polymer generated in the presence and absence of ethyl chloride
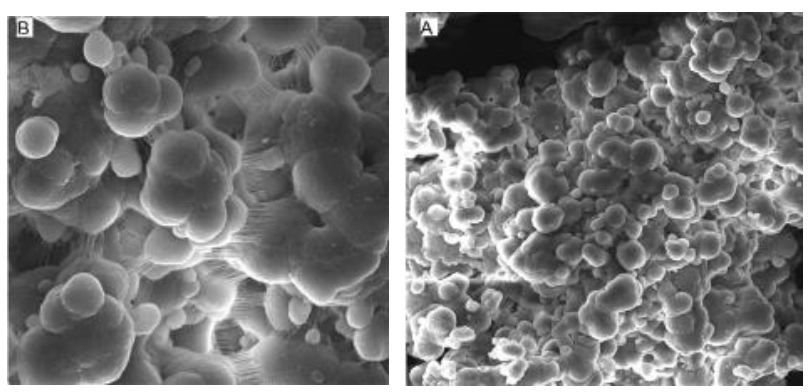

Figure 6. SEM images: (A) polymer powder, (B) polymer powder produced at the presence of ethyl chloride 
$\left(\mathrm{TiCl}_{4} / \mathrm{Mg}(\mathrm{OEt})_{2} / \mathrm{AlEt}_{3}\right)$ in the ethylene polymerization. The molecular weight of the synthesized polymers was reduced in the presence of ethyl chloride and hydrogen. It means that ethyl chloride improved the hydrogen response of the catalyst. The microstructural examination showed that the weight fraction of active sites of I and II types increased; whereas, those of III and IV types reduced and that of V type remained unchanged in the presence of ethyl chloride in the polymerization system. The DSC results indicated that the addition of ethyl chloride decreased the melting point of the produced polymer; whereas, there was no change in the crystallization temperature. The SEM images showed that the produced polymers had the same morphology.

\section{Acknowledgements}

The authors would like to appreciate the Petrochemical Research and Technology Co. of NPC for providing laboratory facilities for this research project and also thank Dr. A. Safinejad for his helps.

\section{References}

[1] Chien, J.C.W., Nozaki, T. (1991). High Activity Magnesium Chloride Supported Catalysts for Olefin Polymerization. XXIX. Molecular Basis of Hydrogen Activation of Magnesium Chloride Supported ZieglerNatta Catalysts. J. Polym. Sci. Pol. Chem., 29: 505-514.

[2] Abedi, S., Hassanpour, N. (2006). Prepration of Bimodal Polypropylene in Two-Step Polymerization. J. Appl. Polym. Sci., 101: 14561462.

[3] Nikolaeva, M.I., Mikenas, T.B., Matsko, M.A., Echevskaya, L.G., Zakharov, V.A. (2011). Ethylene Polymerization over Supported Titanium-Magnesium Catalysts: Effect of Polymerization Parameters on the Molecular Weight Distribution of Polyethylene. J. Appl. Polym. Sci., 122: 3092-3101.

[4] Czaja, K., Białek, M., (2001). Effect of Hydrogen on the Ethylene Polymerization Process over Ziegler-Natta Catalysts Supported on $\mathrm{MgCl}_{2}(\mathrm{THF})_{2}$. II. Kinetic Studies. J. Appl. Polym. Sci., 79: 361-365.

[5] Mazaherian, M., Dashti, A., Mortazavi, M.M., Ahmadjo, S. (2015). Effect of Halocarbon as Promoter on Activity of Ziegler-Natta Catalyst in 1-Hexene Polymerization, The 9 th International Chemical Engineering Congress \& Exhibition (IChEC 2015). 12-26.
[6] Winslow, L.N., Klendworth, D.D., Menon, R., Lynch, M.W., Fields, G.L., Johnson, K.W., (1996). Vanadium-containing Catalyst System. US5534472 A.

[7] Luo, H.K., Tang, R.G., Yang, H., Zhao Q.F., An, J.Y. (2000). Studies on Highly Efficient Promoters for Titanium-based Ziegler-Natta Catalyst for Ethylene Polymerization. Appl. Catal. A Gen., 203: 269-273.

[8] Adisson, E., Deffieux, A., Fontanille, M., Bujadoux, K. (1994). Polymerization of Ethylene at High Temperature by Vanadiumbased Heterogeneous Ziegler-Natta Catalysts. II. Study of the Activation by Halocarbons. J. Polym. Sci. Pol. Chem., 32: 1033-1041

[9] Yang, Y., Kim, H., Lee, J., Paik, H., Jang, H. (2000). Roles of Chloro Compound in Homogeneous $\quad\left[\mathrm{Cr}(2 \text {-Ethylhexanoate })_{3} / 2,5\right.$ Dimethylpyrrole / Triethylaluminum / Chloro Compound] Catalyst System for Ethylene Trimerization. Appl. Catal. A Gen., 193: 2938.

[10] Luo, H.K., Tang, R.G., Gao, K.J. (2002). Studies on the Formation of New, Highly Active Silica-Supported Ziegler-Natta Catalyst for Ethylene Polymerization. J. Catal., 210: 328-339.

[11] Bahri-Laleh, N., Arabi, H., Mehdipor-Ataei, S., Nekoomanesh-Haghighi, M., Zohuri, G., Seifali, M., Akbari, Z. (2012). Activation of Ziegler-Natta Catalysts by Organohalide Promoters: A Combined Experimental and Density Functional Theory Study. J. Appl. Polym. Sci., 123: 2526-2533.

[12] Bohm, L. (1997). Process for the Preparation of a Poly-1-olefin. US5648309 A.

[13] Kang, K.K., Shiono, T., Jeong, Y.T., Lee, D.H. (1999). Polymerization of Propylene by using $\mathrm{MG}(\mathrm{OEt}) 2-\mathrm{DNBP}-\mathrm{TiCl}_{4}$ Catalyst with Alkoxy Disilanes as External Donor. J. Appl. Polym. Sci., 71: 293-301.

[14] Vogel, A.L., Bassett, J. (1978). Vogel's Textbook of Quantitative Inorganic Analysis : Including Elementary Instrumental Analysis. Longman, London, New York.

[15] Kashiwa, N., Yoshitake, J. (1984). The Influence of the Valence State of Titanium in $\mathrm{MgCl} 2$-supported Titanium Catalysts on Olefin Polymerization. Die Makromolekulare Chemie, 185: 1133-1138.

[16] Inoue, M. (1963). Studies on Crystallization of High Polymers by Differential Thermal Analysis. J. Polym. Sci. A Gen., 1: 2697-2709. 
[17] Salajka, Z., Kratochvíla, J., Hudec, P., Věcorek, P. (1993). One-phase Supported Titanium-Based Catalysts for Polymerization of Ethylene. II. Effect of Hydrogen. J. Polym. Sci. Pol. Chem., 31: 1493-1498.

[18] Soares, J.B.P., Hamielec, A.E., (1995). Deconvolution of Chain-Length Distributions of Linear Polymers Made by Multiple-SiteType Catalysts. Polym., 36: 2257-2263.

[19] Ribeiro, M.R, Deffieux, A., Fontanille, M., Portela, M.F. (1995). Homo and Copolymerization of Ethylene: Improvement of Supported Vanadium Catalysts Performance by Halocarbons. Macromol. Chem. Phys., 196: 3833-3844.
[20] Ghafelebashi Zarand, S.M.; Mortazavi, S.M.M., Najafi, M., Haddadi-Asl, V. (2012). Effects of Temperature and Cocatalyst Concentration on the Number of Active Sites in a $\mathrm{TiCl}_{4} / \mathrm{Mg}(\mathrm{OEt})_{2}$ Catalyst for Ethylene Polymerization. J. Petrol. Sci. Technol., 2: 1216.

[21] Richards, R.B. (1951).Polyethylene-structure, Crystallinity and Properties. J. Appl. Chem., 1: $370-376$. 